Journal Of Al-Azhar University Engineering Sector

Vol. 14, No. 50, January, 2019, 99-107

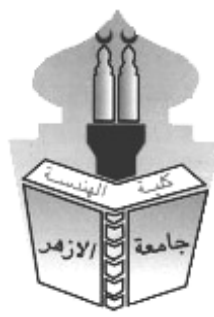

\title{
ASSESSMENT OF OFFSITE POWER RELIABILITY FOR NUCLEAR POWER PLANTS BY FAULT TREE ANALYSIS
}

\author{
A. M. Agwa ${ }^{1}$, E. A. Eisawy ${ }^{2}$ and H. M. Hassan ${ }^{2}$ \\ ${ }^{1}$ Faculty of Engineering - Al-Azhar University \\ ${ }^{2}$ Nuclear and Radiological Regulatory Authority \\ ABASTRACT \\ The reliability of offsite power for a nuclear power plant (NPP) is \\ assessed using fault tree (FT) analysis. The method combines alternating \\ current $(A C)$ load flow analysis with $F$ T technique. The probability of loss \\ of offsite power (LOOP) initiating event is assessed based on the \\ unreliability of the power delivered to the house load of the NPP. Based on \\ the quantitative and qualitative analysis of the constructed $F T$, the \\ probability of the LOOP initiating event is assessed. The FT results \\ include the importance measures which enable identification of the most \\ i mportant elements of the power system from the aspect of nuclear safety. \\ The impact of changes in the power system to the safety of the NPP is \\ evaluated. The verification of the method was performed on the IEEE test \\ system.
}

\section{KEYWORDS: Nuclear Power Plant, Loss of Offsite Power, Fault Tree.}

\section{INTRODUCTION}

NPP safety and the power system reliability are mutually interdependent parameters. The safe operation of the NPP results in delivering a large amount of electrical energy to the power system and contributes to its stable operation. On the other side, the power system delivers the electrical energy to the house load of the NPP, which is especially important during the shutdown and the startup of the NPP. The LOOP initiating event occurs when all electrical power to the plant from electrical grid is lost. In spite of the fact that NPP is equipped with diesel generators in such emergency case, the safety of the NPP is decreased at the LOOP $[1,2]$. The evaluation of the overall system unreliability is very complicated as it is necessary to include detailed modeling of both generation and transmission facilities and their auxiliary elements. A failure of components or subsystems can result in a failure of power delivered to specific loads or in certain cases in a full blackout of the power system.

Many references discussed power system reliability using different approaches. Reliability assessment of Auxiliary Power Supply and its impact on high voltage direct current (HVDC) link is performed by using FT analysis [3]. Statistical analysis of the LOOP registered in four reviewed databases is presented. The number of LOOP events in each year in the analyzed period and mode of operation are assessed during the screening [4, 5]. A case study of power station is considered for performing the FT analysis and the results are presented. The methodology adopted in the investigation is to generate FT for each load point of the power system [6]. FT technique based on generalized fuzzy numbers to a possibility distribution of reliability indices for power systems is described. All the failure probabilities are represented by generalized trapezoidal fuzzy number [7]. A real case study for the US Surry NPP which was touched down by tornado in 2011 causing the electrical switch yard destruction and loss of offsite power is performed. Probabilistic methods have been applied to assess the reliability of the reactor shutdown and effective heat removal after this accident [8]. A method for 
assessing initiating event LOOP probability are reviewed and improved. The probability is assessed and the current plant status and power system are compared to the plant status and power system status [9]. A survey on FT analysis in modeled using reliability assessment of an engineering system using Boolean algebra [10]. A new method for assessment of power system reliability is developed. The method integrates the FT analysis and the power flow model using direct current (DC) model [11-12].

\section{POWER SYSTEM RELIABILITY ANALYSIS}

Most of the approaches for the assessment of power system reliability use approximation or simplification of the problem in order to degrade the problem on a solvable level. The objective of this paper is to assess the reliability of offsite power system for a NPP, using FT analysis technique. The method combines AC load flow method with the FT analysis features. The verification of the method was performed on the institute of Electrical and Electronics Engineers - Reliability Test System (IEEE-RTS-24 bus). The effect of modifications on the power system unreliability are evaluated through $i$ mpli cations of the addition of new line and change of generation and loads. FT analysis is performed using SAPHIRE8 software.

\section{FAULT TREE ANALYSIS}

The FT analysis is a standard method for the assessment and improvement of reliability and safety [13-17]. It has been and it is applied in various sectors, such as nuclear industry. The FT analysis is an analytical technique, where an undesired state of the system is specified and then the system is analyzed in the context of its environment and operation to find all realistic ways in which the undesired event can occur. The undesired state of the system, which is identified at the top of the FT, is usually a state that is critical from a safety or reliability standpoint and is identified as the top event. Top event is therefore an undesired event, which is further analyzed with the FT analysis. The FT analysis is a term that combines the graphical model, which is called FT model, the qualitative analysis and the quantitative analysis (which includes the probabilistic failure data and the associated results).

The logical gates of the FT integrate the primary events to the top event. The primary events are the events that are not further developed, e.g., the basic events (BE). BE are the ultimate parts of the FT, which represent the undesired events and their failure modes, e.g., the component failures, the human errors, the unavailability because of the test and maintenance activities and the common cause failure (CCF) contributions [18].

FT is represented mathematically by a set of Boolean equations. The qualitative analysis (in the process of Boolean reduction of a set of equations) identifies the minimal cut sets (MCS), which are $\mathbb{l}$ ombinations of the smallest number of BE, which, if occur simultaneously, lead to the top ${ }_{\text {quafflative }} \mathrm{I}_{j=1}$ In general, the equations for representing the MCSs as the result of the

where:

$\mathrm{P}_{\mathrm{MCSi}}$ : the probability of occurrence of MCS i

$B_{j}$ : the $B E j$.

$\mathrm{J}$ : number of BEs in a particular MCS.

The quantitative FT analysis represents a calculation of the top event probability, equal to the failure probability of power delivered to the corresponding load. The calculation of the top event probability (using rare event approximation) as [12]:

$$
\boldsymbol{P}_{\text {TOP }}=\sum_{\mathrm{i}=1}^{n} \boldsymbol{P}_{\text {MCS }}
$$

where:

PTOP: the top event probability of the FT.

$\mathrm{n}$ : number of MCSs.

The importance measures are divided in two groups. The first group consists of the measure called Fussell-Vesely Importance (FV) and gives fractional contribution of the BE to the system unreliability. The second group of the importance measures depicts the change of the system unreliability when the contributor's failure probability is set to 0 or 1 . These 
importance measures are named Risk Achievement Worth (RAW) and Risk Reduction Worth (RRW). The three important measures are defined as [18]:

$$
\begin{aligned}
& F V_{i}=1-\frac{P_{T O P_{i}}}{P_{T O P}} \\
& R A W_{i}=\frac{P_{T O P}\left(P_{i}=1\right)}{P_{T O F}} \\
& R R W_{i}=\frac{P_{T O P}}{P_{T O P}\left(P_{i}=0\right)}
\end{aligned}
$$

where:

$\mathrm{FV}_{\mathrm{i}}$ : the Fussel-Vesely importance for BE i.

$\mathrm{P}_{\text {TOPi }}$ : the top event probability for all cut sets containing the BE $\mathrm{i}$.

$\mathrm{RAW}_{\mathrm{i}}$ : the risk achievement worth for BE $\mathrm{i}$.

$\mathrm{P}_{\text {TOP }}\left(\mathrm{P}_{\mathrm{i}}=1\right)$ : the top event probability when failure probability of $\mathrm{BE} \mathrm{i}$ is set to 1 .

$\mathrm{RRW}_{\mathrm{i}}$ : the risk reduction worth for BE $\mathrm{i}$.

$\mathrm{P}_{\text {TOP }}\left(\mathrm{P}_{\mathrm{i}}=0\right)$ : the top event probability when failure probability of BE $\mathrm{i}$ is set to 0 .

\section{FAULT TREE CONSTRUCTION}

The first step in construction of the corresponding FT is identification of all the possible energy flow paths from the adjacency matrix of the corresponding power system. The IEEE 5-bus system shown in Fig. (1), presents an example for the description of the method.

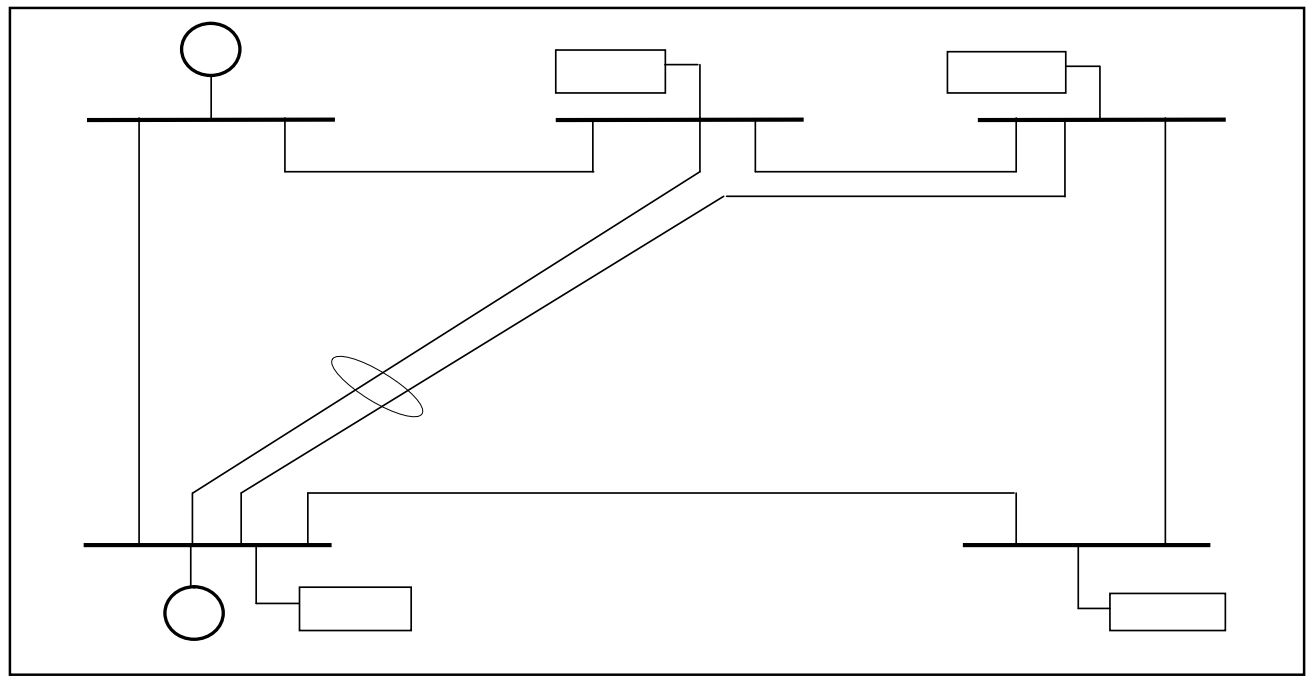

Fig. (1): IEEE 5-bus system

The system consists of five buses, two generators in buses 1 and 2 , and loads in buses 2, 3, 4 and 5. The lines for which CCF are accounted are marked on Fig. (1). The CCF of the part of the line between bus 2 and the buses 3 and 4 is due to common right-of-way for part of their length.

The representation of the system topology is performed through the adjacency matrix $\mathrm{A}$. The adjacency matrix is a matrix with the rows and columns labeled with a 1 or 0 in position (Aij) according to whether the bus $\mathrm{i}$ is connected to bus $\mathrm{j}$ directly or not. The rows follow the running index $\mathrm{i}$ of buses. The columns follow the running index $\mathrm{j}$ of buses. If the value of position Aij is 0 , the buses $\mathrm{i}$ and $\mathrm{j}$ are not directly connected. If the value of position Aij is 1 , the buses $i$ and $j$ are directly connected. The diagonal elements of the matrix equal 0 , as the bus is not connected to itself. The adjacency matrix A of an example system is given on Fig. (2) [23]. 


$$
A=\left[\begin{array}{lllll}
0 & 1 & 1 & 0 & 0 \\
1 & 0 & 1 & 1 & 1 \\
1 & 1 & 0 & 1 & 0 \\
0 & 1 & 1 & 0 & 1 \\
0 & 1 & 0 & 1 & 0
\end{array}\right]
$$

Fig. (2): Adjacency matrix A for IEEE 5-bus system.

The next step is the identification of power flow paths between the load and other buses in system using the rooted tree. A rooted tree is a tree in which a labeled node is singled out. The rooted tree for load 2 is given on Fig. (3)a.

The identified flow paths of energy delivered between buses are tested for consistency as follows:

1. If there is overloaded line in the flow path, then that flow path is rejected.

2. If there is bus with a violated voltage in the flow path, then that flow path is rejected.

Test of overloaded lines in a flow path and voltages in the buses is performed using AC load flow model, using load flow method all active and reactive power flow in the lines and voltage magnitude and angle for each bus in the system are defined. In case of line overloaded above the thermal limits or any voltage magnitude exceed the limits (i.e. $\pm 5 \%$ of rated value), then this branch or bus in not accepted in the FT construction [24].

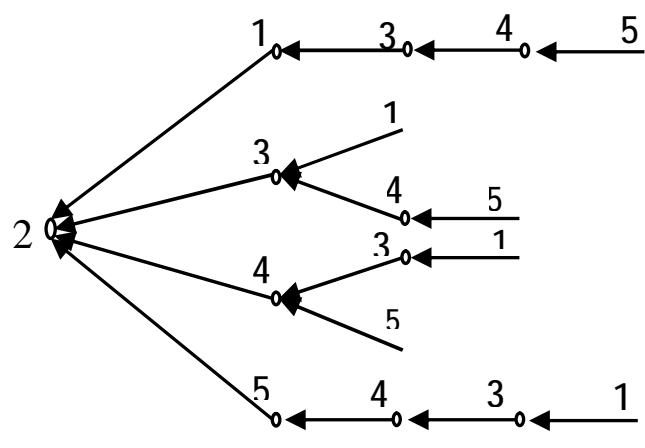

(a) Without consistency

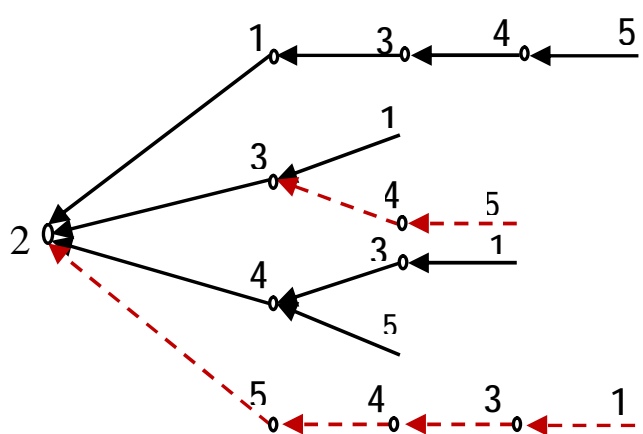

(b) After applying consistency

Fig. (3) a and b: The rooted tree for load 2.

For the IEEE 5-bus power system, let the line between bus 3 and 4 is overloaded for specific flow path corresponding to the power delivered from bus 3 to bus 4 . Also, let the voltage in bus 5 is lower than nominal due to the limited capacity of generator 5. In this case, only flow paths marked with the solid lines are accepted for FT construction. The overloaded line and violated voltage which marked with dashed lines are shown in Fig. (3)b.

Flow paths accepted in previous test of consistency, are used in next step for the FT construction. The FT constructed for the load 1 of the example system, is created using the modular FT as shown in

Fig. (4) 


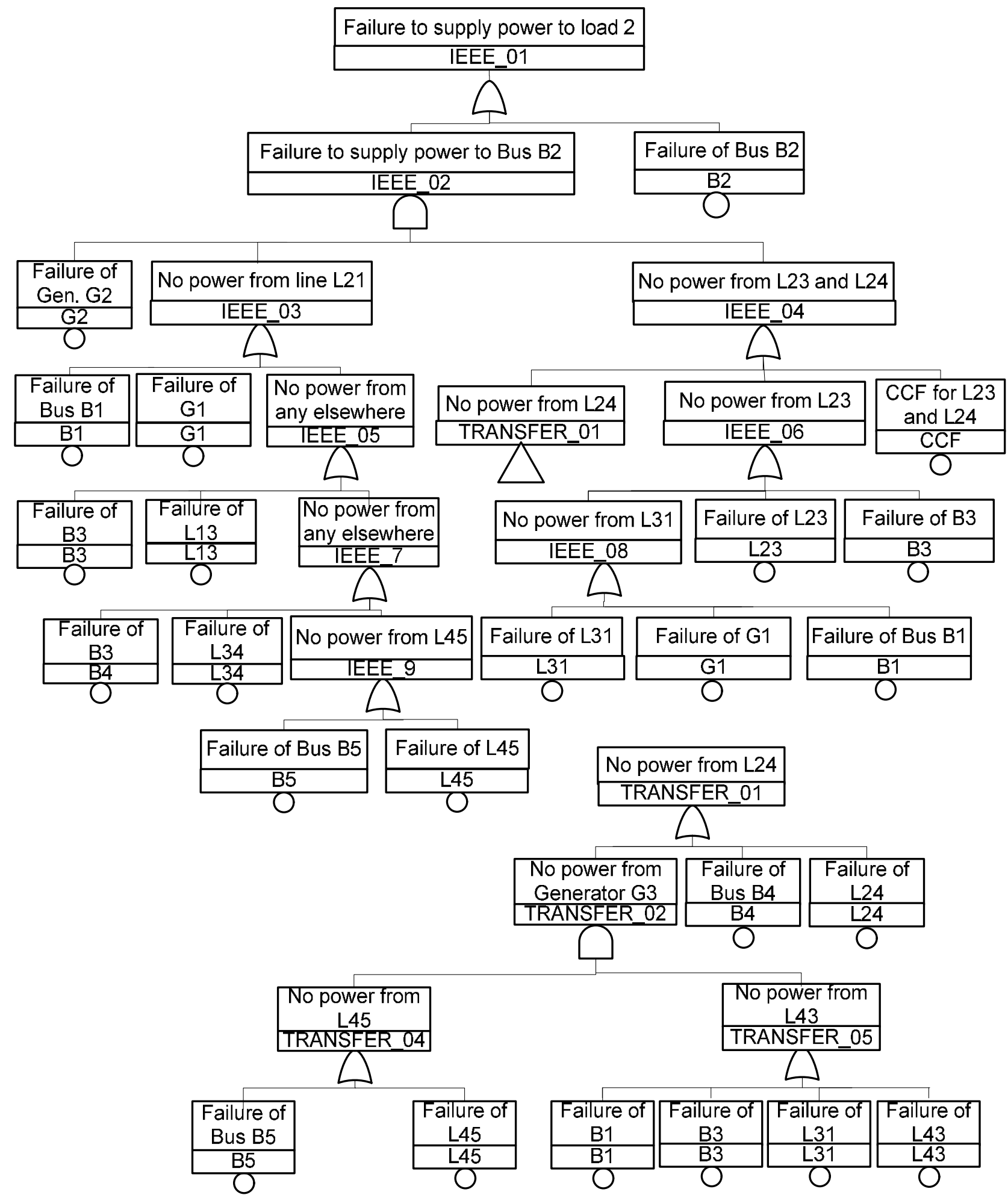

Fig. (4): The fault tree built for load 2.

\section{CASE STUDY AND RESULTS}

The verification of the method was performed on the IEEE-RTS 24-bus, the system consisting of 24 buses (18 buses directly connected to loads and 7 buses directly connected to generators), 32 generators and 38 power lines. For 14 lines, CCF are considered [25]. The IEEE reliability test system is specially designed to be used for different static and dynamic analyses and to compare the results obtained by different methods. Diagram of the IEEE-RTS 24-bus is given in Fig. (5). 


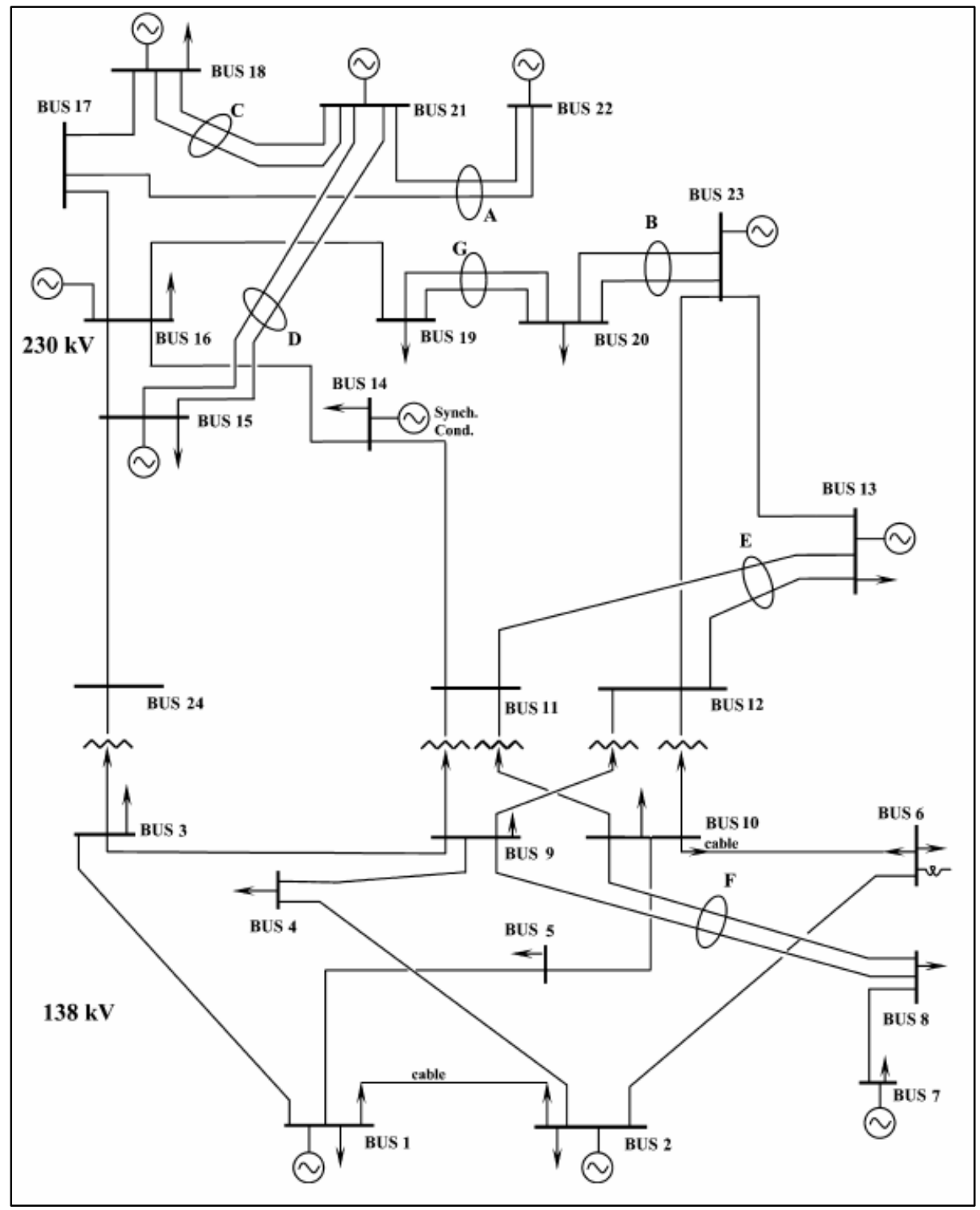

Fig. (5): IEEE-RTS 24-bus single line diagram

The NPPs in the IEEE-RTS 24-bus are situated in the buses 18 and 21 allowing testing of the applicability of the method for estimation of the LOOP initiating event probability for the corresponding NPP. The load of size 20 MW was added in the bus 21 in order to account house load of the NPP in the analysis. The available data for component reliability are used in the analysis [25].

The following results are obtained for the selected loads (loads 21 and 18):

B FT model and top event probability,

ß Unreliability (i.e. LOOP initiating event probability),

ß FV importance for all elements of the system,

B RAW for all elements of the system,

B RRW for all elements of the system and

B Unreliability comparison of several configurations with different modifications of the system.

In FT construction it is assumed that NPP generators (bus 21 and 18) can't run in house load operation mode (i.e. they can't supply their own load only). FT analysis is done using Systems Analysis Programs for Hands-on Integrated Reliability Evaluations (SAPHIRE-8) software [18].

The quantitative and qualitative results of the FT analysis are presented in Tables (1) and (2): 
Table (1): Identified MCS for power delivered to the load in the bus 21.

\begin{tabular}{|c|c|c|}
\hline$\#$ & Probability & Cut Set \\
\hline Total & $4.477 \mathrm{E}-5$ & Displaying 10 of 1155 Cut Sets. \\
\hline 1 & $4.430 \mathrm{E}-5$ & BUS-21 \\
\hline 2 & $2.304 \mathrm{E}-8$ & GEN-14,GEN-15-6,GEN-16,GEN-18,GEN-21,GEN-22-1 \\
\hline 3 & $2.304 \mathrm{E}-8$ & GEN-14,GEN-15-6,GEN-16,GEN-18,GEN-21,GEN-22-5 \\
\hline 4 & $2.304 \mathrm{E}-8$ & GEN-14,GEN-15-6,GEN-16,GEN-18,GEN-21,GEN-22-4 \\
\hline 5 & $2.304 \mathrm{E}-8$ & GEN-14,GEN-15-6,GEN-16,GEN-18,GEN-21,GEN-22-3 \\
\hline 6 & $2.304 \mathrm{E}-8$ & GEN-14,GEN-15-6,GEN-16,GEN-18,GEN-21,GEN-22-2 \\
\hline 7 & $1.302 \mathrm{E}-8$ & GEN-15-6,GEN-16,GEN-18,GEN-21,LINE-21-22 \\
\hline 8 & $1.152 \mathrm{E}-8$ & GEN-14,GEN-15-1,GEN-16,GEN-18,GEN-21,GEN-22-1 \\
\hline 9 & $1.152 \mathrm{E}-8$ & GEN-14,GEN-15-3,GEN-16,GEN-18,GEN-21,GEN-22-1 \\
\hline 10 & $1.152 \mathrm{E}-8$ & GEN-14,GEN-15-2,GEN-16,GEN-18,GEN-21,GEN-22-1 \\
\hline
\end{tabular}

Table (2): Identified MCS for power delivered to the load in the bus 18

\begin{tabular}{|l|l|l|}
\hline$\#$ & Probability & Cut Set \\
\hline Total & $6.969 \mathrm{E}-4$ & Displaying 10 of 294 Cut Sets. \\
\hline 1 & $5.760 \mathrm{E}-4$ & GEN-16,GEN-18,GEN-21 \\
\hline 2 & $5.268 \mathrm{E}-5$ & CCF-LINE-18-21,GEN-18 \\
\hline 3 & $4.430 \mathrm{E}-5$ & BUS-18 \\
\hline 4 & $9.763 \mathrm{E}-6$ & GEN-18,GEN-21,LINE-22-17 \\
\hline 5 & $6.322 \mathrm{E}-6$ & GEN-18,GEN-21,LINE-17-16 \\
\hline 6 & $5.789 \mathrm{E}-6$ & GEN-18,GEN-21,LINE-17-18 \\
\hline 7 & $6.379 \mathrm{E}-7$ & GEN-18,GEN-21,BUS-22 \\
\hline 8 & $6.379 \mathrm{E}-7$ & GEN-18,GEN-21,BUS-17 \\
\hline 9 & $6.379 \mathrm{E}-7$ & GEN-18,GEN-21,BUS-16 \\
\hline 10 & $2.126 \mathrm{E}-7$ & GEN-16,GEN-18,BUS-21 \\
\hline
\end{tabular}

Tables (1) and (2) show the ten most important MCS identified from the FT built for the loads in the bus 21 and 18 respectively, BE (BUS-21) corresponds to the failure of the bus 21 . The $\mathrm{BE}$ (GEN-21) corresponds to the failure of the generator in the bus 21, BE (GEN-15 and 6) corresponds to the generator 6 failure in bus 15, and $\mathrm{BE}(\mathrm{GEN}-18)$ corresponds to the failure of the generator in the bus 18. Line failures are identified with the BE (LINE-21-22) corresponding to the failure of the line between bus 21 and bus 22, BE (CCF-LINE-18-21) corresponds to the CCF of the lines between bus 18 and 21.

The top event for load 21 is 4.477E-5 which corresponds to the probability of LOOP for that load. Similarly LOOP probability for load 18 is $6.969 \mathrm{E}-4$. The LOOP probability for load 18 is higher because it has less connections to the grid (thee transmission lines) compared to five transmission lines for load 21. The largest important measures for loads 21 and 18 is given in Tables (3) and (4) respectively. Table (3) shows that bus 21, generators 21,18 and 16 has the highest FV, RAW and RRW values. Table (4) shows that generators 18, 21 and 16 and CCF between lines 18 and 21 has the highest FV and RRW values.

Table 3: Basic events with the largest important measures for load 21.

\begin{tabular}{|l|l|l|l|l|l|}
\hline Name & Prob. & FV & RAW & RRW & Description \\
\hline BUS-21 & $4.430 \mathrm{E}-05$ & $9.895 \mathrm{E}-01$ & $2.234 \mathrm{E}+04$ & $9.558 \mathrm{E}+01$ & Bus 21 Failure \\
\hline GEN-21 & $1.200 \mathrm{E}-01$ & $1.046 \mathrm{E}-02$ & $1.077 \mathrm{E}+00$ & $1.011 \mathrm{E}+00$ & Gen. 21 Failure \\
\hline GEN-18 & $1.200 \mathrm{E}-01$ & $1.042 \mathrm{E}-02$ & $1.076 \mathrm{E}+00$ & $1.011 \mathrm{E}+00$ & Gen. 18 Failure \\
\hline GEN-16 & $4.000 \mathrm{E}-02$ & $1.034 \mathrm{E}-02$ & $1.248 \mathrm{E}+00$ & $1.010 \mathrm{E}+00$ & Gen. 16 Failure \\
\hline
\end{tabular}


Table 4: Basic events with the largest important measures for load 18.

\begin{tabular}{|l|l|l|l|l|l|}
\hline Name & Prob. & FV & RAW & RRW & Description \\
\hline GEN-18 & $1.200 \mathrm{E}-01$ & $9.365 \mathrm{E}-01$ & $5.777 \mathrm{E}+00$ & $1.573 \mathrm{E}+01$ & Gen. 18 Failure \\
\hline GEN-21 & $1.200 \mathrm{E}-01$ & $8.606 \mathrm{E}-01$ & $2.739 \mathrm{E}+00$ & $7.168 \mathrm{E}+00$ & Gen. 21 Failure \\
\hline GEN-16 & $4.000 \mathrm{E}-02$ & $8.268 \mathrm{E}-01$ & $5.350 \mathrm{E}+00$ & $5.770 \mathrm{E}+00$ & Gen. 16 Failure \\
\hline CCF-LINE-18-21 & $4.390 \mathrm{E}-04$ & $7.559 \mathrm{E}-02$ & $1.730 \mathrm{E}+02$ & $1.082 \mathrm{E}+00$ & CCF for line 18 - 21 A and B \\
\hline
\end{tabular}

Several configurations of the IEEE-RTS are analyzed. Table (5) shows the effect of modification on the unreliability of power delivered to the selected loads, and it shows also the basic and different configurations added to the model. The modifications are as follows:

Case 1: adding a new generator (with rate $155 \mathrm{MW}$ ) at bus 17.

Case 2: adding new load (with rate $100 \mathrm{MW}, 20 \mathrm{MVAR}$ ) at bus 17.

Case 3: adding new load (with rate $150 \mathrm{MW}, 20 \mathrm{MVAR}$ ) at bus 22.

Case 4: adding a single line between bus 22 and bus 23 .

Table (5) shows different unreliability for different configuration of the test system. The worst configuration is adding a new load at bus 22 which increase significantly the unreliability of the power delivered to the house load for NPP at bus 21, and consequent I y increase the LOOP initiating event probability. On the other hand, when a new generator at bus 17 is added, the unreliability of the power delivered at bus 18 is significantly decreased.

Table (5): Summarized results for the IEEE-RTS 24-bus

\begin{tabular}{|l|c|c|}
\hline Case Description & Probability (load 21) & Probability (load 18) \\
\hline Basic configuration & $4.477 \mathrm{E}-05$ & $6.969 \mathrm{E}-04$ \\
\hline Case 1 & $4.43 \mathrm{E}-05$ & $1.27 \mathrm{E}-04$ \\
\hline Case 2 & $4.84 \mathrm{E}-05$ & $6.97 \mathrm{E}-04$ \\
\hline Case 3 & $5.68 \mathrm{E}-05$ & $6.97 \mathrm{E}-04$ \\
\hline Case 4 & $4.44 \mathrm{E}-05$ & $6.97 \mathrm{E}-04$ \\
\hline
\end{tabular}

\section{CONCLUSION}

FT technique and AC load flow analysis are used to assess the probability of the LOOP initiating event based on the unreliability of the power delivered to the house load of the NPP. The results are qualitative and quantitative and they depend on the failure probabilities of the components, load flow and topology of the power system. The obtained results include identified MCS, unreliability of the power delivered to the corresponding loads and the importance measures of components corresponding to selected loads. Results of both quantitative and qualitative help in focusing attention on those sections of a power system that contribute the most to the unreliability of power delivered to the house load of the NPP. The method is applied on IEEE-RTS 24-bus. Several configurations of the test system are analyzed and therefore the modifications effect on the system unreliability are presented.

\section{REFERENCES}

[1] Nyman, Lauri, and Sakke Rantala. "Development of a probabilistic risk analysis example using a computer tool for dynamic event tree modeling.", 2016.

[2] Li, Zhiping, "Loss of Offsite Power Frequency Calculation II", Probabilistic Safety Assessment and Management PSAM 12, June 2014.

[3] $\mathrm{Yu}, \mathrm{Lu}$, "Fault tree analysis and reliability assessment of auxiliary power supply system for an HVDC plant", Diss. Royal Institute of Technology, 2007.

[4] Volkanovski, Andrija, Antonio Ballesteros Avila, and Miguel Peinador Veira, "Statistical Analysis of Loss of Offsite Power Events", Science and Technology of Nuclear Installations, 2016. 
[5] Andrija Volkanovski, Antonio Ballesteros, Miguel Peinador, "Summary Report on Events Related to Loss of Offsite Power and Station Blackout at NPPs", JRC technical report, 2016.

[6] Jaise, J., et al., "Power system: a reliability assessment using FTA", International Journal of System Assurance Engineering and Management 4.1, pages: 78-85, 2013.

[7] Verma, Manjit, Amit Kumar, and Yaduvir Singh, "Power system reliability evaluation using fault tree approach based on generalized fuzzy number", Journal of Fuzzy Set Valued Analysis, 2012.

[8] Mieczysław Borysiewicz, Aleksej Kaszko, Karol Kowal, Sławomir Potempski, "Loss of offsite power caused by tornado in Surry NPP - a case study", Journal of Polish Safety and Reliability Association Summer Safety and Reliability Seminars, Volume 6, Number 3, 2015. [9] Marko Čepin, "Assessment of Loss of Offsite Power Initiating Event Frequency", $23^{\text {rd }}$ international conference nuclear energy for new Europe, 2014.

[10] Daochuan Ge, Shanqi Chen, Zhen Wang, Zhibin Chen, "Dynamic Fault Tree Analysis for NPP Emergency Diesel Generator System", Transactions of the American Nuclear Society, Vol. 118, Philadelphia, Pennsylvania, June 17-21, 2018.

[11] A. Volkanovski, "Impact of offsite power system reliability on nuclear power plant safety", PhD thesis, University of Ljubljana, 2008.

[12] A. Volkanovski, Marko Cepin, and Borut Mavko, "Application of the fault tree analysis for assessment of power system reliability", Reliability Engineering \& System Safety 94.6, 2009.

[13] Henley, Ernest J., and Hiromitsu Kumamoto, "Probabilistic risk assessment and management for engineers and scientists", IEE Press, New York, USA, 1996.

[14] Cepin, Marko, and Borut Mavko, "A dynamic fault tree", Reliability Engineering \& System Safety 75.1, 2002.

[15] Čepin, Marko, "Method for assessing reliability of a network considering probabilistic safety assessment", Proc. Int. Conf. Nuclear Energy for New Europe, 2005.

[16] Cepin, Marko, "Development of new method for assessing reliability of a network", Proceeding of PSAM8, New Orleans, USA, 2006.

[17] Kančev, Duško, et al., "Application of probabilistic safety assessment for macedonian electric power system", International Conference Nuclear Energy for New Europe, Portorož, 2007.

[18] C. L. Smith and S. T. Wood, "Systems Analysis Programs for Hands-on Integrated Reliability Evaluations (SAPHIRE): Version 8", US Nuclear Regulatory Commission, Office of Nuclear Regulatory Research, 2011.

[19] David A. Nelson, "Introduction to fault tree analysis." 2012 Annual Reliability and Maintainability Symposium. USA. 2018.

[20] Fazlollahtabar, Hamed, and Seyed Taghi Akhavan Niaki. "Fault Tree Analysis for

Reliability Evaluation of an Advanced Complex Manufacturing System." Journal of

Advanced Manufacturing Systems17.01, pp. 107-118, 2018.

[21] Joost-Pieter Katoen and Matthias Volk, "A Modern Perspective on Fault Tree Analysis", RWTHAACHEN university, Byline, 2018.

[22] Bhandakkar, Anjali Atul. "Real-Time-Simulation of IEEE-5-Bus Network on OPAL-RTOP4510 Simulator." IOP Conference Series: Materials Science and Engineering. Vol. 331. No. 1. IOP Publishing, 2018.

[23] Ray D. Zimmerman, Carlos E. Murillo-Sanchez, "Matpower 5.1 User's Manual”, Power Systems Engineering Research Center (Pserc), 2015.

[24] Kaushik Paul, Niranjan Kumar, "Application of MATPOWER for the Analysis of Congestion in Power System Network and Determination of Generator Sensitivity Factor", international Journal of Applied Engineering Research, ISSN 0973-4562 Volume 12, Number 6, pp.969-975, 2017.

[25] Ordoudis, C., Pinson, P., Morales González, J. M., \& Zugno, M., “An Updated Version of the IEEE RTS 24-Bus System for Electricity Market and Power System Operation Studies", Technical University of Denmark (DTU), 2016. 